\section{BÀN LUẬN}

Nghiên cứu cho chỉ số Lasègue, dấu hiệu Bonnet và dấu hiệu Néri, điểm đau Vaillex ở cả hai nhóm sau điều trị đều cải thiện có ý nghĩa thống kê $(p<0,05)$, mức độ cải thiện chỉ số Lasègue trung bình của nhóm 1 nhiêu hơn nhóm $2(p<0,05)$. Phác đồ điện châm nghiên cứu dùng nhóm huyệt tại chỗ kích thích lên vị trí đau theo đường kinh bị bệnh kết hợp với nhóm huyệt toàn thân nên tăng hiệu quả giảm đau [4], [5]. Kết hợp với bài thuốc Độc hoạt tang ký sinh có tác dụng trừ phong thấp, bổ can thận phù hợp để điều trị thể bệnh của bệnh nhân nghiên cứu nên có tác dụng giảm đau khá tốt [2]. Thuốc thuỷ châm Golvaska (Mecobalamin) là chế phẩm dạng Coenzym của Vitamin $B_{12}$ có trong máu và dịch não tủy, được vận chuyển vào mô thân kinh cao hơn các dạng khác của Vitamin $B_{12}$. Mecobalamin có tác dụng phục hồi những mô thân kinh bị tổn thương và ngăn chặn sự dẫn truyền các xung thân kinh bất thường, do đó có tác dụng điều trị hội chứng chèn ép rể thần kinh thắt lưng.

Sau điều trị, cả hai nhóm đều có sự cải thiện chức năng sinh hoạt hàng ngày theo thang điểm Owestry Disability ( $p<0,01)$, trong đó nhóm 1 cải thiện nhiều hơn nhóm $2(p<0,01)$. Thoái hóa cột sống thắt lưng gây đau do co cứng cơ cạnh sônng, co rút các gân cơ, dây chằng... làm tắng chèn ép rễ thần kinh, chèn ép rễ thân kinh lại gây đau tạo lên vòng xoắn bệnh lý, biểu hiện bằng những hạn chế sinh hoạt hàng ngày của bệnh nhân [4]. Việc cải thiện hội chứng chèn ép rễ thần kinh thắt lưng cũng sẽ cải thiện những hạn chế trong sinh hoạt hàng ngày. Nghiên cứu chưa thây xuất hiện tác dụng không mong muốn trên lâm sàng và cận lâm sàng.

\section{KẾT LUẬN}

1. Thủy châm thuốc Golvaska có tác dụng cải thiện hội chứng chèn ép rễ thần kinh thẳt lưng và chức năng sinh hoạt hàng ngày ở bệnh nhân đau thân kinh hông to do thoái hóa cột sônng.

2. Chưa thấy tác dụng không mong muốn nào trên lâm sàng và cận lâm sàng.

\section{TÀI LIỆ THAM KHẢO}

1. Nguyễn Nhược Kim, Trân Quang Đạt (2008). Châm cứu và các phương pháp chữa bệnh không dùng thuốc. Nhà xuât bản Y học, $205-218,223-225$.

2. Nguyến Nhược Kim (2015). Vai trò của $Y$ học cổ truyên kết hợp Y học hiện đại trong điều trị một số bệnh cỡ xương khớp, Nhà xuất bản y hoc, $30-35$.

3. Nguyễn Thị Ngọc Lan (2012). Bểnh học $c 0$ xương khớp nội khoa. Nhà xuất bản giáo dục Việt Nam, 24-25, $152-159$.

4. Berman $B M$, Langevin $H M$, Witt $C M$ et al (2010). "Acupuncture for chronic low back pain", N Engl J Med, 363, pp. 454 - 461.

5. Chen Mei-ren, Wang Ping, Cheng Gang, Guo Xiang, Wei Gao-wen, Cheng Xu-hui (2009). The Warming Acupuncture for treatment of Sciatica in 30 cases. Journal of Traditional Chinese Medicine, 29(1), $50-53$.

6. Fairbank JC, Davis JB (1996). The oswestry low back pain disability question physiotherapy, $271-273$

\title{
TỰ CHỦ TÀI CHÍNH BÊNNH VIÊ̂N ĐA KHOA TỈNH LÀO CAI GIAI ĐOẠN 2015 - 2019: MộT Số KHÓ KHĂN VÀ THUÂ̂N LỢI
}

\section{TÓM TẮT}

Mục tiêu: Nghiên cứu được thực hiện để tìm hiểu yếu tổ ảnh hưởng đến quá trình thực hiện tự chủ tài chính của bệnh việnĐa khoa tỉnh Lào Cai giai đoạn 2015-2019. Phương pháp nghiên cứu: Thiết kế nghiên cứu định tính sứ dụng kỹ thuật phỏng vấn sâu và thảo luận nhóm với đại diện ban giám đốc bệnh viện, lãnh đạo phòng/ban chức năng,giám định viên BHYT, cán bộ quản lý tại khoa, cán bộ quản lý vật tư - trang thiết bị y tế tại Bệnh việnĐa khoa tỉnh Lào Cai.

${ }^{1}$ Trường Đại học Y tế Công cộng

${ }^{2}$ Bênh viện đa khoa tỉnh Lào Cai

Chịu trách nhiệm chính: Nguyễn Quỳnh Anh

Email: nqa@huph.edu.vn

Ngày nhâan bài: 6.01 .2021

Ngày phản biên khoa họ: 5.3.2021

Ngày duyệt bài: 12.3.2021

\section{Nguyễn Quỳnh Anh', Phạm Văn Thinh ${ }^{2}$}

Kết quả: Chính sách công khai thu chi, chi tiêu nội bộ, khen thưởng xử phạt, quy mô và chất lượng khám chữa bệnh, chẩt lượng và số lượng nguồn nhân lực, cơ sở vật chất, trang thiết bi là những yếu tố nội tại ảnh hưởng trực tiếp đến quá trình thực hiện tự chủ tài chính của bệnh viện. Kết luận:Để quá trình thực hiện tự chủ tài chính đạt hiệu quả Bệnh viện cần tiếp tục chú trong chất lượng dịch vụ y tế, tăng cường phát triểndịch vụ kỹ thuật mới, dịch vụ kỹ thuật theo yêu cầu, nâng cao năng lực đội ngũ cán bô quản lý tà chính, thường xuyên mở các lớp tập huấn, bồi dưỡng các chế độ chính sách mới về quản lý tài chính nhằm nâng cao nhận thức, thay đổi thái độ, hành vi của cán bộ bệnh viện.

Từ khóa: Tự chủ tài chính,yếu tố ảnh hưởng, điểm mạnh điểm yếu, Bệnh viện Đa khoa tỉnh Lào Cai

\section{SUMMARY}

FINANCIAL AUTONOMY AT LAO CAI 
GENERAL HOSPITAL, PERIOD 2015- 2019 - SOME DIFFICULTIES AND ADVANTAGES

Objectives: The study was conducted to find out the difficulties and advantages of the Lao Cai General Hospital in the process of implementing financial autonomy in the period 2015 - 2019. Methods: Design a qualitative study using in-depth interviews and group discussions with representatives of hospital directors, functionaldepartmentleaders, health insurance assessors, department administrators, materials and medical equipment management staff at the Lao Cai General Hospital. Results: Policies for disclosing revenues and expenditures, internal expenditures, rewards and sanctions, scale and quality of medical examination and treatment, quality and quantity of human resources, facilities and equipment are intrinsicfactors that directly affect the hospital financial autonomy implementation. Conclusion: In order for being successful in the financial autonomy, the hospital should continue to focus on the quality of medical services, strengthen the development of new technical services, on-demand technical services, and improve capacity of financial management staff, regularly opening training classes, fostering new financial management policies to raise awareness, change attitudes and behaviors of hospital staff.

Keywords: Financial autonomy, influencing factors, strengths and weaknesses, Lao Cai general hospital

\section{I. ĐẶT VẤN ĐỀ}

Cơ chế tự chủ tài chính đối với các đơn vị sự nghiêp công lập có thu là cơ chế theo đó các đơn vị sự nghiệp công được trao quyền tự quyết định, tự chịu trách nhiệm về các khoản thu, khoản chi của đơn vị mình nhưng không vượt quá mức khung do Nhà nước quy định. Căn cứ vào định mức kinh tế kỹ thuât, chế đô chi tiêu tài chính hiện hành của Nhà nước, đơn vị sự nghiệp có thu được chủ động xây dựng tiêu chuẩn, định mức và chể đố chi tiêu nội bộ cho các khoản chi hoạt đông thường xuyên cao hơn hoăc thấp hơn quy định, trong phạm vi nguồn tài chính được sử dụng; đảm bảo hoạt động thường xuyên, thực hiên nhiêm vư được giao, phù hợp với đăc điểm đớn vị, tăng cường công tác quản lý và sử dung kinh phí tiết kiệm có hiệu quả, thông qua việc xây dựng quy chế chi tiêu nội bộ (1). Có thể thấy, cơ chế tự chủ tài chính nhấn mạnh đến năng lực quản lý của lãnh đạo các đơn vị sự nghiêp công lập, trong đó có các bệnh viện công lập.

Bênh viện Đa khoa (BVĐK) tỉnh Lào Cai, là bệnh viện Đa khoa hạng I tuyến cuối của tỉnh trực thuộc Sở y tế tỉnh Lào Cai. Cùng với các bệnh viện công lập khác trong toàn quốc, BVĐK tỉnh Lào Cai cũng trong lộ trình tự chủ tài chính. Ngày 15 tháng 10 năm 2012, Chính phủ đã ban hành Quyết định số 58/2012/ND-CP về cơ chế hoạt động, cơ chế tài chính đối với các đơn vị y tế công lâp. Năm 2015 bênh viên đa khoa tỉnh Lào Cai đã thực hiện tự chủ 72\%, năm 2016 tự chủ $76 \%$, năm 2017 tự chủ $86 \%$ và năm 2018 , 2019 tự chủ $88 \%$, theo tiến trình tự chủ trong Nghi quyết của Hối đồng nhân dân tỉnh Lào Cai thì bệnh viện sẽ thực hiện tự chủ hoàn toàn $100 \%$ chi thường xuyên vào năm $2022(2,3)$. Với việc tự chủ hoàn toàn về tài chính, bệnh viện phải tự cân đối thu, chi để đảm bảo các hoat động và phát triển đơn vị. Do đó, nhu cầu cấp thiết đặt ra lúc này là phải hiểu rõ điểm mạnh, điểm yếu của chính bênh việncó ảnh hưởng đến thu chi tài chính để chuẩn bị cho việc tự chủ hoàn toàn về tài chính trong tương lai. Vì vậy, chúng tôi tiến hành nghiên cứu "Tìm hiểu một số yếu tốảnh hưởng đến quá trình thực hiệntự chủ tài chính tại Bênh viện đa khoa tỉnh Lào Cai giai đoạn 2015-2019".

\section{II. ĐỐI TƯợNG VÀ PHƯƠNG PHÁP NGHIÊN CỨU}

Nghiên cứu định tính, bao gồm thảo luận nhóm và phỏng vấn sâu.

Thời gian và địa điểm nghiên cứu: Nghiên cứu được thực hiện từ tháng 10/2019 đến tháng 11/2020 tai bênh viên Đa khoa tỉnh Lào Cai.

\section{Phương pháp chọn mẫu:}

*Thảo luận nhóm: Tổ chức 2 cuộc thảo luận nhóm với nhân viên y tế, số lượng mẫu mỗi nhóm từ 4-6 người. Để nội dung thảo luận có trọng tâm, nhóm thảo luận đã được chia theo các nhóm cùng trình độ chuyên môn hoặc cùng lĩnh vực, bộ phận công tác: Bác sỹ các trưởng khoa lâm sàng (nhóm 1) và Điều dưỡng khoa lâm sàng (nhóm 2).

*Phỏng vấn sâu: Tổ chức 7 cuộc phỏng vấn sâu với các đối tượng: (1) lãnh đạo bệnh viện, (2) trưởng phòng Kế hoạch tổng hợp, (3) trưởng phòng Tài chính kế toán, (4) trưởng phòng Tồ chức cán bộ, (5) trưởng phòng Điêuu dưỡng, (6) giám định viên BHYT, (7) cán bộ quản lý vật tư trang thiết bị y tế tại Bệnh viện.

Chon mẫu có chủ đích: Chon những người có thời gian làm việc tại Bệnh viện trên 6 năm, có hiểu biết chuyên mồn và thẳng thắn, sẵn sàng chia sẻ thông tin.

Phương pháp thu thập số liệu:Thảo luận nhóm, phỏng vấn sâu được thực hiện với các đối tượng tại phòng làm việc của đối tượng được phỏng vấn, sử dụng bộ câu hỏi chuẩn bị trước cho từng đối tượng. Thời gian mỗi cuộc thảo luận nhóm khoảng 2 tiếng và phỏng vấn sâu là 30-45 phút. Nội dung thảo luận nhóm, phỏng vấn sâu được ghi âm, đồng thời sẽ ghi chép thêm những thông tin ghi chú cần thiết. 
Chủ đề nghiên cứu định tính: Tập trung khai thác một sốyếu tố chủ quan ảnh hưởng trong quá trình thực hiện tự chủ tài chính của bệnh viện đa khoa tỉnh Lào Cai giai đoạn 20152019, bao gồm: Chính sách công khai thu chi, chi tiêu nội bộ, khen thưởng xử phạt, quy mô và chất lượng khám chữa bệnh, chất lượng và số lượng nguồn nhân lực, cơ sở vật chất, trang thiết bị.

\section{KẾT QUẢ NGHIÊN CỨU}

\section{Kết quả cân đôii thu chi tai bênh viên giai đoan 2015 - 2019}

Bảng 3.1. So sánh số dự toán, thực hiện các khoản thu chi, giai đoạn 2015 - 2019

\begin{tabular}{|c|c|c|c|c|c|}
\hline \multicolumn{1}{|c|}{ Chỉ tiêu } & $\mathbf{2 0 1 5}$ & $\mathbf{2 0 1 6}$ & $\mathbf{2 0 1 7}$ & $\mathbf{2 0 1 8}$ & $\mathbf{2 0 1 9}$ \\
\hline Tống thu dự toán & 195.094 & 240.984 & 265.550 & 285.043 & 288.586 \\
\hline Tống thu thực hiện & 226.278 & 248.089 & 268.111 & 273.018 & 322.709 \\
\hline Chênh lệch thu thực hiện/dự toán & 31.184 & 7.105 & 2.561 & -12.025 & 34.123 \\
\hline Tỳ lệ hoàn thành dự toán thu & $116 \%$ & $103 \%$ & $101 \%$ & $96 \%$ & $112 \%$ \\
\hline Tống chi dự toán & 185.573 & 225.721 & 256.250 & 266.232 & 276.024 \\
\hline Tống chi thực hiện & 210.956 & 229.214 & 257.534 & 256.068 & 305.759 \\
\hline Chênh lệch chi thực hiện/dự toán & 25.383 & 3.493 & 1.284 & -10.164 & 29.735 \\
\hline Tỵ lệ chi thực tế/dự toán & $114 \%$ & $102 \%$ & $101 \%$ & $96 \%$ & $111 \%$ \\
\hline Nộp NSNN & 402 & 438 & 521 & 396 & 557 \\
\hline Chênh lệch thu-chi & 15.322 & 18.875 & 10.578 & 16.950 & $16.949,70$ \\
\hline
\end{tabular}

Nhìn chung tổng chi và thu thực hiên đều vượt mức dự toán. Lây 2015 làm gốc thì chênh lệch thu chi của bệnh viện có xu hướng tăng.

3.1. Chính sách công khai thu chí, chi tiêu nội bộ, khen thưởng xử phạt ảnh hưởng đến tư chủ tài chính bênh viền. Sau khi kết thúc năm kế toán, Phòng Tài chính Kế toán bệnh viện lập các báo cáo kế toán, báo cáo tài chính, báo cáo quyết toán thu, chi gửi Sở Y tế tỉnh Lào Cai xét duyệt theo quy định hiện hành:

"... Các loại báo cáo tài chính cơ bản được lập đầy đủ và gứi đúng thời gian quy định. Số liệu báo cáo được phản ánh trung thực, chính xác. Nội dung các báo cáo tài chính luôn theo đúng các nội dung ghi trong dự toán được duyệt vào đúng Mục lục NSNN đã quy định." - (PVS - 01)

Bênh viện đã xây dựng và ban hành quy chế chi tiêu nội bộ nhằm quản lý, sử dụng các nguồn thu chi đúng mục đích, phù hợp khả năng, tình hình thực tế. Điều này đã giảm thiểu đáng kể những hiện tượng không lành mạnh gây thất thoát trong đơn vị:

"...quy chế chi tiêu nội bộ giúp cho bệnh viện chi tiêu kinh phí hợp lý hơn, đồng thời gẳn trách nhiệm của cán bộ viên chức bệnh viện trong việc thực hiện nhiệm vụ, từ đó sử dụng hiệu quả các nguồn lực và có thể tiết kiệm chi phí..."- (PVS 04), hay "...trong quy chế chi tiêu nội bộ của bệnh viện cũng đưa các quy định về việc tiết
Phương pháp phân tích số liệu: Sắp xếp các bản ghi chép và băng phỏng vẩn sâu. Tiến hành gõ băng, mã hóa theo chủ đề và trích dẫn theo mục tiêu nghiên cứu

Đạo đức nghiên cứu: Nghiên cứu được tiến hành sau khi Hội đồng Đạo đức Nghiên cứu Y Sinh học trường Đại học $Y$ tế công cộng xem xét và phề duyệt thổng qua theo cổng văn số $295 / 2020 /$ YTCC-HD3 ngày 14/7/2020.
18.875

kiệm điện, văn phòng phẩm và sử dụng chi phí công tác phí hợp lý, và giảm thiểu tối đa việc mua sắm các thiết bị chưa cân thiết" -(TLN-02)

Song song với việc xây dựng các quy chế chi tiêu tài chính nội bộ, nhằmtạo động lực kinh tế hơn cho đội ngũ cán bộ viên chức, bệnh viện đã xây dựng và áp dụng các chế độ khen thưởng xử phạt nhằm động viên, nâng cao tinh thần trách nhiệm, khuyển khích nhân viên cố gắng hoàn thành tốt công việc, điều này được thể hiện rõ thông qua thông tin định tính thu được:

"... cán bộ viên chức toàn bệnh viện phải xác định rõ nguồn thu nhập của tất cả nhẩn viên phụ thuộc vào số lượng người đến khám chữa bệnh, nên nhân viên phải làm việc tích cực, nhiệt tình, tận tâm, trách nhiệm, làm sao ngày càng nhiều bệnh nhân tin tưởng lựa chọn bệnh viện này."(PVS - 01)

Tuy nhiên trong công tác chấp hành dự toán thu, chi tài chính bệnh viện, vẫn tồn tại những bấp cập nhất định, như:

"... Trong quá trình thực hiện công tác quyết toán, còn một số bộ phận thực hiện còn chậm, chưa tập hợp, rà soát hểt các khoản thu, nhiệm vụ chi; chưa tập hợp đầy đủ hồ sơ, chứng từ thực hiện khóa sổ kế toán; lập báo cáo còn thiếu một số mẫu biểu theo quy định, số liệu còn chưa chính xác" - (PVS - 03)

"Công tác kiểm tra, giám sát, đánh giá tình 
hình quản lý tài chính ngân sách vẫn còn hình thức, khi phát hiện những sai phạm chưa xử lý kịp thời, chế tài chưa đủ mạnh, chủ yếu dừng ở mức nhắc nhở, rút kinh nghiệm hoặc khi phát hiên sai phạm chỉ xử lý thu hồi nộp ngân sách bệnh viện nhưng chưa quy trách nhiệm và xử lý quyết liệt đối với cá nhân vi phạm" - (TLN - 01)

3.2. Quy mô và chất lượng khám chữa bênh ảnh hưởng đến tự chủ tài chính bênh viện. Trong giai đoạn 2015 - 2019, Bệnh viện đa khoa tỉnh Lào Cai đã tích cực đầu tư nâng cấp, sửa chữa, nâng cao chất lượng cơ sở vật chất, cải tiến chất lượng công tác khám bênh, chữa bệnh, tăng cường thêm các phòng khám và các phòng thực hiện cận lâm sàng: siêu âm, chụp $X Q$ nhằm giảm thời gian chờ đợi cho người bệnh.

"...Bệnh viện đã thực hiện sửa chữa và đưa vào sử dụng: khu khám chữa bệnh cho cán bộ tỉnh quản, khu khám chữa bệnh theo yêu cầu,... đã góp phần giảm tình trạng quá tải, giảm nhiều thời gian chờ đợi khám chữa bệnh với sự tăng hài lòng của người bệnh đến khám và điều trị tại viện." - (PVS -01)

Trong giai đoạn 2015 - 2019, Bệnh viện đã triển khai nhiều kỹ thuật mới trong khám, chữa bệnh góp phần nâng cao chất lượng khám chữa bệnh, thu hút người bệnh, tăng nguồn thu cho bệnh viện,như:

".. mấy năm vừa qua, bệnh viện đã triển khai nhiều kỹ thuật mới, ví dụ như: tán sỏi thận qua da, phẫu thuật thay khớp háng, phẫu thuật tái tạo dây chằng chéo khớp gối, kĩ thuật điều trị tai biến bằng thuốc tiêu sợi huyết, phẫu thuật khối máu tụ trong não,.." - (PVS - 06)

Khoa Huyết học truyền máu và hóa sinh vi sinh đã được trang bị đầy đủ trang thiết bị đểphục vụ công tác chuyên môn ngày một tốt hơn: "Khoa Huyết học truyền máu và hóa sinh vi sinh đã được trang bị đầy đủ trang thiết bị cơ bản phục vụ công tác chuyên môn, một số trang thiết bị đã được thay thế và trang bị mới (máy ly tâm máu, máy đo độ đông nửa, tủ ẩm, tủ ân sâu,....)." - (PVS - 04)

Công tác nghiên cứu khoa học và sinh hoạt khoa học kỹ thuật nhằm nâng cao trình độ chuyên môn của nhân viên y tế tại bệnh viện cũng rất được quan tâm:

"...trong 5 năm 2015 - 2019, Bệnh viện đã tiến hành nghiệm thu 45 đề tài, tổ chức 60 buổi sinh hoạt khoa học kỹ thuật. Trong giai đoạn 2015 - 2019, bệnh viện đã tổ chức 18 hội thảo khoa học với các chủ đề liên quan đến các kỹ thuật điều trị mới, hiệu quả giúp nâng cao trình độ chuyên môn cho đội ngũ y bác sĩ tại bệnh viện." - (PVS - 05)

Hoạt động cải tiến chất lượng bệnh viện tại Bệnh viện đa khoa tỉnh Lào Cai được quan tâm thực hiện thường xuyên. Kết quả kiểm tra đánh giá chất lượng bệnh viện tại Bệnh viện giai đoạn 2015 - 2019 luôn đạt điểm cao nhất trong tỉnh, kết quả phỏng vấn sâu cho thây:

"... Kết quả kiểm tra đánh giá chất lượng bênh viện tại Bệnh viện đa khoa tỉnh Lào Cai từ nắm 2015 - 2019 luôn đạt điểm cao nhất cụ thể năm 2016 đạt 3,12/5 điểm, năm 2017 đạt 3,50/5 điểm, năm 2018 đạt 3,72/5 và năm 2019 đạt 3,59/5 điểm." - (PVS - 01)

Với các giải pháp thực hiện để nâng cao chất lượng dịch vụ khám chữa bệnh như vậy, Bệnh viện đa khoa tỉnh Lào Cai đã phải chi nhiều kinh phí, cùng với chất lượng dịch vụ nâng cao, sô lượng người đến khám và điều trị bệnh tại bệnh viện cũng tăng cao, góp phần tăng nguồn thu cho bệnh viện.

\subsection{Nhân lực bệnh viện ảnh hưởng đến} tự chủ tài chính bệnh viện. Nhân lực của bệnh viện Đa khoa tỉnh Lào Cai giai đoạn 20152019 có số lượng tăng dần qua các năm, từ 611 người năm 2015 tăng lên hơn 623 người năm 2019. Trong đó số lượng bác sĩ tăng đáng kể, từ năm 2015 đến năm 2019 tăng 31 người. Trong cơ chế tự chủ tài chính, theo nguyên lý, bên canh việc tư chủ về tài chính, các cơ sở y tế công lập còn được tự chủ về tổ chức nhân lực. Kết quả phỏng vấn sâu cho biết:

"... Với quy mô khám chữa bệnh ngày càng mở rộng và phát triển, từ 500 giường bệnh nội trú năm 2015 tăng lên gần 800 giường vào năm 2019 đòi hỏi nguồn nhân lực cũng phải tăng theo để đáp ứng quy mô và sự phát triển của đơn vị"- (PVS - 02)

Trong giai đoạn 2015 - 2019, bệnh viện Đa khoa tỉnh Lào Cai đẩy mạnh công tác đào tạo nguồn nhân lực vì vậy chất lượng nguồn nhân lực của bệnh viện Đa khoa tỉnh Lào Cai không ngừng được nâng cao. Điều này được thể hiện qua số liệu và kết quả phỏng vấn sâu, thảo luận nhóm: "... Chỉ trong 5 năm, từ 2015- 2019, số lượng bác sỹ chuyên khoa I, II, thạc sỹ của bệnh viện đã tăng đáng kể, góp phần nâng cao chất lượng khám bệnh, uy tín cho Bệnh viện"-(PVS-02)

"... Lãnh đạo bệnh viện tạo điều kiện thuận lợi cho nhân viên trong học tập nâng cao trình độ như: hỗ trợ kinh phí học tập, tạo điều kiện về thời gian, mở các lớp đào tạo ngay tại bệnh viện, đã góp phần nâng cao trình độ nhân viên một cách nhanh chóng" - (TLN - 01)

Không chỉ có Bác sĩ được học tập nâng cao 
trình độ, lực lượng điêu dưỡng của Bệnh viện cũng tích cực học tập nâng cao trình độ:

"...trong giai đoạn 2015- 2019 đã có 15 điều dưỡng nâng trình độ từ trung cấp, cao đẳng lên cử nhân điêu dưỡng. Các chương trình đào tạo tại chỗ, khóa học ngắn hạn cho điều dưỡng, y sĩ và các nhân viển khác được Bệnh viện tồ chức thường xuyên" - (PVS - 02)

Tuy nhiên khó khăn nhất của bệnh viện là chưa được tự chủ nhân lực, vì vậy mà số lượng và chất lượng nhân lực đều chưa đáp ứng được nhu cầu. "... Bệnh viện không được tự chủ về nhân lực, việc tuyển dụng là do sở $Y$ tế và phân bổ nhân viên về bệnh viện nên nhiều khi người làm việc tại bệnh viện đã có kinh nghiệm lại không được tuyển, có những vị trí tuyển không đúng nhu cầu đặc biệt là các đối tượng điều dưỡng, kĩ thuật viên gẩy áp lực rất lớn cho điều dưỡng, vừa phải làm chuyên môn lại phải đào tạo người mới thêm nữa việc nghỉ bù nghỉ trực, đi học nghỉ chế độ làm cho nhân viên rất mêt mỏi, quá tải. Dù có điều động nhân lực giữa các khoa cũng không phù hợp được" - (PVS - 05)

Việc quy định công chức, viên chức tại bệnh viện đa khoa tỉnh Lào Cai vẫn phải thực hiện theo quy định của Luật Công chức, Luật Viên chức dẫn đến khá nhiêu khó khăn cho bệnh viện trong quá trình cơ cấu lại nhân sự phù hợp với định hướng phát triển của bệnh viện:

"...nói là tự chủ bệnh viện nhưng thực chất chính phủ mới chỉ mở cửa về tự chủ tài chính. Các mặt khác khá quan trọng về nhân sự, tổ chức... chưa được tự chủ, từ đó kéo theo rất nhiều khó khăn, vướng mắc cho bệnh viện..."(PVS - 01)

Một trong những bất cập khác tại bênh viện hiên nay chỉ mới cử được một số cán bô nòng cốt của phòng tài chính kế toán đi học chuyên sâu, một số cán bộ tài chính kế toán còn yếu về kỹ năng chuyên môn, thêm vào đó tổ chức bộ máy kế toán của bênh viện còn chưa đáp ứng được yêu cầu khi chuyển sang cơ chế tự chủ, chưa thực hiện đầy đủ chức năng tham mưu vế tài chính cho cán bộ lãnh đạo của bệnh viện:

"... trình độ chuyên môn của một số cán bộ phòng tài chính kế toán còn chưa vững." - (TLN-01)

"...bệnh viện chỉ mới tổ chức bộ máy kế toán theo các phần công việc mà chưa được tổ chức và bố trí cán bộ nhân viên kế toán cụ thể thực hiện công việc phân tích thông tin thu chi tài chính, phục vụ cho lãnh đạotrongviệc lập kế hoạch và ra các quyết định quản trị nội bộ..." (PVS - 03)

Nhận thức cũng như năng lực của một bộ phận cán bộ viên chức bệnh viện đối với thực hiện tự chủ tài chính còn nhiều hạn chế, phần nào ảnh hưởng đến việc cải thiện chất lượng dịch vụ khám chữa bệnh hay nâng cao nguồn thu sự nghiệp cho bệnh viện:

"...vẫn còn không ít nhân viên y tễ và người lao động trong bệnh viện chưa nhận thức đúng và đủ về cơ chế tự chủ, về xu thể tất yếu cần đổi mới hoạt động của bệnh viện, do vậy mà vẫn còn tư tưởing ỳ lại vào sự bao cấp của nhà nước, chưa chủ động học tập và thay đổi tác phong phục vụ người bệnh" - (PVS - 06)

\subsection{Cơ sở vật chất, trang thiết bị ảnh} hưởng đến tự chủ tài chính bệnh viện. Cơ sở vật chất của Bệnh viện sử dụng được hơn 6 năm đã có dấu hiệu xuống cấp và ảnh hưởng đến hoạt động khám chữa bệnh cũng như hoạt động chung của bệnh viện rất nhiều. Vì vậy, trong giai đoạn 2015 - 2019, Bệnh viện chi nhiều kinh phí để đẩy mạnh công tác sửa chữa cơ sở vật chất đặc biệt là sửa chữa máy móc phục vụ khám chữa bệnh.

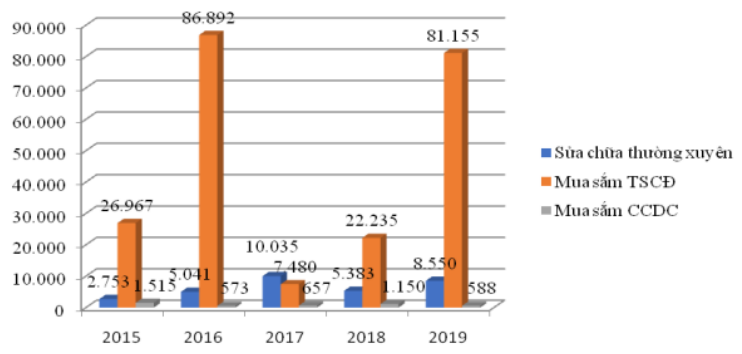

\section{Biểu đồ 3.1. Chi tài sản cố định, công cụ} dung cu, giai đoan 2015 - 2019

Số liệu biểu đổ cho thấy, tổng chi cho công tác sửa chữa thường xuyên giai đoạn 2015 2019 là 31,762 tỉ đồng. Chi phí mua sắm tài sản cố định hàng năm từ 2015-2019 ngày càng tăng cao, năm 2016 lên tới 86,892 tỉ đồng.

"... Bệnh viện được xây mới, cở sở vật chất ban đầu cũng khá khang trang, tuy nhiên sau vài năm có dấu hiệu thấm dột, ẩm mốc rất mất mỹ quan và tốn nhiều chi phí sửa chữa đến nay vẫn chưa khắc phục được. Trang thiết bị cũng được đầu tư mới nhưng thường xuyên gặp vấn đề, chi phí sửa chữa tốn kém do không tìm được linh kiện thay thế, ảnh huởng rất lớn tới tài chính bệnh viện" - (PVS - 05)

Do được đầu tư nâng cấp, mở rộng cơ sở vật chất mà số giường bệnh thực tế của bệnh viện Đa khoa tỉnh Lào Cai tăng đáng kể trong giai đoạn 2015 - 2019, góp phần tăng nguồn thu cho bệnh viện. "... số giường bệnh thực tế của bệnh viện tăng đáng kể trong giai đoạn 2015 - 2019, 
từ 500 giường năm 2015 tăng lên gần 700 giường năm 2019, tăng 1,6 lần" - (PVS - 04)

\section{BÀN LUÂN}

Viêc giao quyền tự chủ tài chính cho bênh viện thời gian qua đã có tác động đến việc phát huy tính sáng tạo và chủ động của đơn vị. Bệnh viện đã xây dựng và ban hành quy chế chi tiêu nội bộ nhằm quản lý, sử dụng các nguồn thu chi đúng mục đích, phù hợp khả năng, tình hình thực tế. Điều này đã giảm thiểu đáng kể những hiện tượng không lành mạnh gây thất thoát trong đợn vị. Song song với việc xây dựng các quy chế chi tiêu tài chính nội bộ, nhằmtạo động lực kinh tế hơn cho đội ngũ cán bộ viên chức, bệnh viện đã xây dựng và áp dụng các chế độ khen thưởng xử phạt nhằm động viên, nâng cao tinh thần trách nhiệm, khuyến khích nhân viên cố gắng hoàn thành tốt công việc. Như vậy có thể thấy, dựa trên các nghị định của Chính phủ, thông tư hướng dẫn thực hiển của Bộ $Y$ tế vế việc tự chủ tại các đơn vị sự nghiệp công lập, bệnh viện Đa khoa tỉnh Lào Cai đã chủ động cụ thể hoá các nghị định, thông tư đó thông qua việc xây dựng và thực hiện các quy định, quy chế liên quan đến tài chính, phù hợp với điều kiện, hoàn cảnh thực tế và áp dụng triệt để, nhận được sự ủng hộ của nhân viên y tế và người lao động trong bệnh viện.

Một trong những khó khăn lớn nhất của bệnh viện Đa khoa tỉnh Lào Cai là thiếu trâm trọng nguồn nhân lực đặc biệt là nhân lực chất lượng cao. Nhân lực còn thiếu về cả số lượng và chất lượng ảnh hưởng tiêu cực đến quá trình thực hiện tự chủ của bệnh viện. Một trong những bất cập khác tại bệnh viện hiện nay chỉ mới cử được một số cán bộ nòng cốt của phòng tài chính kế toán đi học chuyên sâu, một số cán bộ tài chính kế toán còn yếu về kỹ năng chuyên môn, thêm vào đó tổ chức bộ máy kế toán của bệnh viện còn chưa đáp ứng được yêu cầu khi chuyển sang cơ chế tự chủ, chưa thực hiện đầy đủ chức năng tham mưu về tài chính cho cán bộ lãnh đạo của bệnh viện.

Về quy mô, chất lượng khám chữa bệnh của bệnh viện ngày càng được nâng cao là yếu tố góp phần tăng nguồn thu. Trong giai đoạn 2015 - 2019, quy mô bệnh viện ngày càng tăng, từ 500 giường năm 2015 lên 700 giường kế hoạch năm 2020 và tiếp tục có xu hướng tăng vì bệnh viện đã được phê duyệt thành lập thêm 03 trung tâm, Bệnh viện đã tích cực đầu tư nâng cấp, sửa chữa, nâng cao chất lượng cơ sở vật chất, cải tiến chất lượng công tác khám bệnh, chữa bệnh, tăng cường thêm các phòng khám và các phòng thực hiện cận lâm sàng. Tuy nhiên, việc sửa chữa còn chậm do ảnh hưởng của việc quyết toán và thời gian khám chữa bệnh và công việc sửa chữa cũng đem lại nhiều bất cập như gẩy tiếng ồn, mất mĩ quan khiến giảm lượng lớn bệnh nhân, giảm nguồn thu của bệnh viện. Đây là những ảnh hưởng tiêu cực đến quá trình tự chủ tài chính của bệnh viện. Điều này tương đồng với nghiên cứu của tác giả Nguyễn Văn Hinh thực hiện năm 2020 (4) về việc cơ sở vật chất là yếu tố ảnh hưởng tới hoạt động thu chi tài chính của bệnh viện $Y$ dược học dân tộc Thành phố Hồ Chí Minh.

\section{KẾT LUÂ̂N VÀ KHUYẾN NGH!}

Nghiên cứu đã phân tích điểm mạnh điểm yếu của bệnh viện Đa khoa tỉnh Lào Cai trong quá trình thực hiện tự chủ tài chính giai đoạn 2015-2019. Theo kết quả nghiên cứu cho thấy, chính sách công khai thu chi, chi tiêu nội bộ, khen thưởng xử phat, quy mô và chất lượng khám chữa bệnh, chất lượng và số lượng nguî̀n nhân lực, cớ sở vật chất, trang thiết bị ảnh hưởng trực tiếp đến quá trình thực hiện tự chủ tài chính của bệnh viện.

Để quá trình thực hiện tự chủ tài chính đạt hiệu quả Bệnh viện cần tiếp tục phát huy và tăng cường các nguồn thu và tiết kiệm chi cho bệnh viện thông qua xây dựng phương án và đẩy mạnh công tác khám chữa bệnh, chú trọng chất lượng dịch vụ y tế, tăng cường phát triểndịch vụ kỹ thuật mới, dịch vụ kỹ thuật theo yêu câu, nâng cao năng lực đội ngũ cán bộ quản lý tài chính thông qua việc cử đi học tập, bồi dưỡng nâng cao trình độ trong các lớp đào tạo ngắn/dài hạn, thường xuyên mở các lớp tập huấn, bồi dưỡng các chế độ chính sách mới về quản lý tài chính nhất là các văn bản mới liên quan đến cơ chế tự chủ tài chính nhằm nâng cao nhận thức, thay đổi thái độ, hành vi của cán bộ bệnh viện.

\section{TÀI LIÊU THAM KHẢO}

1.Bộ Y tế. Thông tư số 15/2007/TT - BYT ngày 12/12/2007. Về việc hướng dẫn thực hiện quyền tự chủ, tự chịu trách nhiệm về việc sử dụng tài sản để liên doanh, liên kết hợ̆c góp vốn liên doanh để mua sắm trang thiết bị phục vụ hoạt động dịch vụ tai các cơ sở y tế công. 2007.

2. Bềnh viên đa khoa tỉnh Lào Cai. Báo cáo kết quả thực hiện các chỉ tiêu kế hoach giai đoạn 2015-2019 và xây dưng kế hoạch giai đoạn 2016-2020.

3. Bệnh viện đa khóa tỉnh Lào Cai. Báo cáo quyết toán tài chính từ năm 2015-2019

4. Nguyển Văn Hinh. Thực trang hoat động thu chi tài chính và một số yếu tố ảnh hưởng tại viện Y dước dân tộc thành phố Hồ Chí Minh giai đoan 2016-2018: Trường Đại học Y tế Công cộng; 2020. 